\title{
A Study to Assess the Knowledge on Pre-Eclampsia Toxaemia among Antenatal Mothers
}

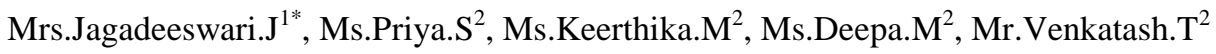 \\ ${ }^{1}$ Department of Obstetrics Gynaecological Nursing, Saveetha College of Nursing, SIMATS, Chennai, Tamil Nadu, India \\ ${ }^{2}$ B.Sc (N) IV yr Students, Saveetha College of Nursing, SIMATS, Chennai, Tamil Nadu, India
}

DOI: $10.36348 /$ sijog.2020.v03i04.003 $\quad$ | Received: 02.03.2020 | Accepted: 10.03 .2020 | Published: 25.04 .2020

*Corresponding author: Mrs. Jagadeeswari.J

\section{Abstract}

Pre-eclampsia is characterized by high blood pressure (hypertension), fluid retention (oedema) and excessive protein levels in the urine (proteinuria). These symptoms are not evident during the early stages of pregnancy and as such preeclampsia can be difficult to diagnose. It is only detectable by regular antenatal checks on maternal blood pressure and urine, and as such women without access to adequate healthcare services are particularly at risk. This study intended to assess the knowledge regarding Pre-Eclampsia Toxemia among antenatal mothers. A descriptive study was conducted in primary health centre outpatient department at Karanchavadi with 50 samples who were recruited by non-probability convenient sampling technique. Data gathering was carried out with a semi structured questionnaires and the major findings of the study reveals that $8(16 \%)$ had adequate knowledge, $15(30 \%)$ had moderate knowledge and $27(54 \%)$ had inadequate knowledge on Pre-Eclampsia Toxemia among antenatal mother. There are significant associations between levels of knowledge with demographic variables such as age and occupation. The study suggests creating the awareness among the antenatal mothers by an awareness among antenatal mother help in improve their health.

Keywords: Knowledge, Pre-Eclampsia Toxemia and Antenatal Mother.

Copyright @ 2020: This is an open-access article distributed under the terms of the Creative Commons Attribution license which permits unrestricted use, distribution, and reproduction in any medium for non-commercial use (NonCommercial, or CC-BY-NC) provided the original author and source are credited.

\section{INTRODUCTION}

Pre-eclampsia is characterized by high blood pressure (hypertension), fluid retention (oedema) and excessive protein levels in the urine (proteinuria). These symptoms are not evident during the early stages of pregnancy and as such preeclampsia can be difficult to diagnose. It is only detectable by regular antenatal checks on maternal blood pressure and urine, and as such women without access to adequate healthcare services are particularly at risk $[1,2]$.

Pre-Eclampsia Toxaemia is a pregnancyassociated multisystem disorder with no definite aetiology. The primary cause of PE is still under investigation. However, it is thought to occur in two stages. The first stage encompasses the impairment of foetal trophoblastic invasion of the decidua and local placental hypoxia. The second stage is the release of placental blood-related factors into the maternal circulation and aberrant expression of pro- inflammatory, antiangiogenic and angiogenic factors [3].

Pre-Eclampsia Toxaemia is usually characterized by elevated blood pressure and proteinuria, with the clinical manifestation usually occurring during the 20th week of gestation or late in pregnancy and regressing post-delivery. It is grouped into two main types: early-onset Pre-Eclampsia Toxaemia (occurring before 34 weeks of gestation) and late-onset Pre-Eclampsia Toxaemia (occurring after 34 weeks of gestation). Although the presenting features of early- and late-onset PE may overlap, earlyonset Pre-Eclampsia Toxaemia is associated with increased odds of complications, particularly preterm birth, foetal growth restriction and maternal morbidity and mortality compared to late onset Pre-Eclampsia Toxaemia. Women with Pre-Eclampsia Toxaemia also present with diverse signs and symptoms associated with multiple organ systems. Headaches, visual disturbances, abnormal kidney function, severe 
hypertension, chest pain, pulmonary oedema and low oxygen saturation, nausea and abnormal liver function are among the common outcomes of the multi-organ system dysfunction in Pre-Eclampsia Toxaemia. Risk factors of Pre-Eclampsia Toxaemia include first pregnancy, age (pregnancy at an advanced age or under 18 years of age), family history of Pre-Eclampsia Toxaemia, personal history of Pre-Eclampsia Toxaemia, obesity, gestational diabetes, multifetal gestation and pre-existing medical conditions such as chronic hypertension[4-6].

Pre-Eclampsia Toxaemia remains one of the leading causes of maternal mortality and morbidity, complicating an estimated $2-8 \%$ of pregnancies worldwide and up to $10 \%$ in developing countries. It is one of the top five leading causes of maternal and neonatal deaths. Pre-Eclampsia Toxaemia can progress to eclampsia and cause adverse foetal outcomes such as preterm birth, small-for-gestational-age babies, placental abruption, and perinatal death and increase the risk of cardiovascular and cerebrovascular diseases and venous thromboembolism later in life. Furthermore, women who suffer from Pre-Eclampsia Toxaemia are predisposed to mental health issues such shame, guilt, feelings of failure, loss of control, personal inadequacy and postpartum depression [7, 8].

Adequate knowledge about a disorder contributes greatly to its prevention, control and management. Reports indicate that patients' knowledge about a disease has significant benefits on compliance to treatment and helps to abate complications associated with the disease. In India, one major hurdle in combating Pre-Eclampsia Toxaemia is the late reporting of women to healthcare centres following an experience of a sign or symptom. Pre-Eclampsia Toxaemia is a disease of signs and symptoms which requires prompt attention. Equipped with knowledge, women experiencing Pre-Eclampsia Toxaemia would report early to the hospital, receive timely medical intervention and have fewer adverse outcomes. This emphasizes the need for women to have adequate knowledge of the disease [9].

There is currently no way of curing preeclampsia. In severe cases the only way to relieve the mother's symptoms is to artificially induce delivery or to prematurely deliver the child by emergency caesarean section. Being born prematurely can have serious consequences and every year four million babies are born with fetal growth restriction as a consequence of preeclampsia. This study, being an attempt to assess the level of knowledge of PE, its symptoms, complications, risk factors and evaluated the factors associated with knowledge adequacy among antenatal mothers attending antenatal care at a selected primary health center.

\section{METHODOLOGY}

A quantitative approach with descriptive research design was used to conduct the study to assess the knowledge about pre-eclampsia toxemia among antenatal mothers in primary health centre at Kariyanchavadi. The data were collected using a Nonprobability convenient sampling technique with 50 antenatal mothers who met the inclusion criteria. The inclusion criteria for sampling are antenatal mothers who are willing to participate in the study, who can understand, read, write, and speak, Tamil and English and antenatal mother who can follow the instruction. The data were collected after obtaining ethical clearance from the Institutional Ethical Committee of Saveetha Institute of Medical Science and Technology. The reason for the investigation was disclosed to the subjects and assent was got from them. The demographic variables consists of antenatal mothers age, education, socio economic status, number of pregnancies, disease condition and structured questionnaires was used to assess the knowledge about pre- eclampsia toxemia among antenatal mothers. The data was organized with descriptive and inferential statistics.

\section{RESULT}

The major findings of the study reveals that $52 \%$ of mothers were in the age group of $25-30$ years, $42 \%$ of mothers had secondary education, $60 \%$ of mothers were house wives, $66 \%$ of mothers live in nuclear family and $58 \%$ of mothers had previous exposure of pre- eclampsia toxemia.

Table-1: Frequency and Distribution of level of knowledge on pre eclamptic toxemia among antenatal mothers

\begin{tabular}{|c|c|c|}
\hline Level of Knowledge & $\begin{array}{c}\text { Frequency } \\
(\mathbf{N})\end{array}$ & $\begin{array}{c}\text { Percentage } \\
\mathbf{\%}\end{array}$ \\
\hline Adequate & 8 & $16 \%$ \\
\hline Moderate & 15 & $30 \%$ \\
\hline Inadequate & 27 & $54 \%$ \\
\hline
\end{tabular}

TABLE 1: reveals that $8(16 \%)$ have adequate knowledge; $15(30 \%)$ have moderate knowledge; $27(54 \%)$ have inadequate knowledge. 
Jagadeeswari.J et al; Sch Int J Obstet Gynec, April. 2020; 3(4): 124-126

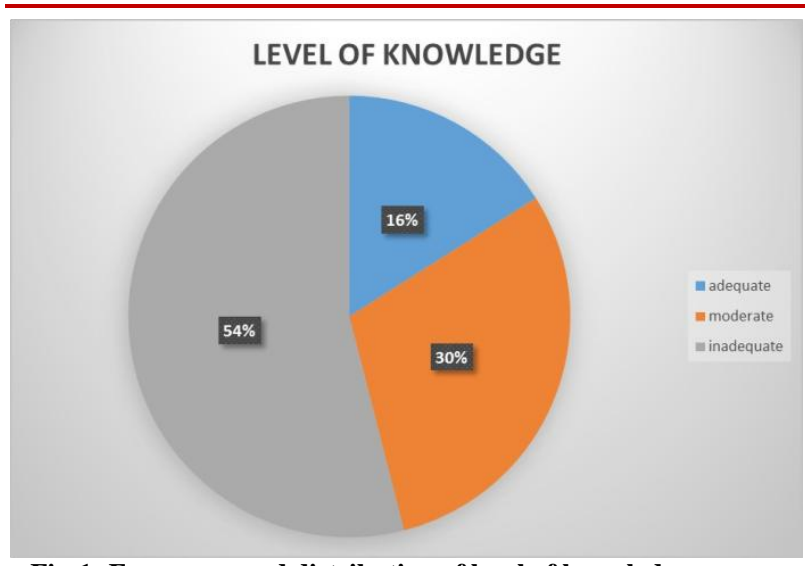

Fig-1: Frequency and distribution of level of knowledge on pre eclamptic toxemia among antenatal mothers

There are significant associations between levels of knowledge with demographic variables such as age and occupation.

\section{DISCUSSION}

The major findings of the study reveals that 8 (16\%) had adequate knowledge, 15 (30\%) had moderate knowledge and 27 (54\%) had inadequate knowledge. There are significant associations between levels of knowledge with demographic variables such as age and occupation.

The present study is supported by Zuo, Tey \& Teng, See \& Keng, Soon \& Jummaat, Fauziah. Knowledge of Preeclampsia among antenatal women in a tertiary referral teaching hospital. Data analysis of level of knowledge revealed minority of mothers (18.4\%) had adequate knowledge with a mean score of $53.46( \pm 26.42)$. Maternal age and receipt of information toward preeclampsia showed an association with knowledge scores at 0.05 level of significance. The study showed a need for awareness program and public education about preeclampsia among antenatal mothers [10]. Another study which supports the present study is Divyaben Trivedi, Mr. Ravindra H.N. who conducted a study to assess the effectiveness of structured teaching programme on knowledge regarding pre - eclampsia among antenatal mothers at Selected Rural Areas. In pretest there were $21 \%$ participants in average knowledge and no participants having good knowledge [11].

\section{CONCLUSION}

The study findings reveal that most of the mothers had inadequate knowledge about PreEclampsia Toxemia so the study suggests creating the awareness among the antenatal mothers by awareness among antenatal mother help in improve their health.

\section{REFFERENCE}

1. American College of Obstetricians and Gynecologists. (2002). Diagnosis and management of preeclampsia and eclampsia. Obstet. Gynecol., 99, 159-167.

2. Adele, P. (2002). Text book for Maternal and Child Health Nursing. 4th Edition. Wippincon William. New York, 404-410

3. Alan H. De Cherney Lauren Nathan. (2001). Current Obstetrics and Gynecology diagnosis and treatment, 9th Edition Lang medical books M/c Grow Hill publishers Los Angeles, California,349353

4. Alexander, F. B. (2002): “Text Book of clinical obstetrics and gynecology "Black well science Ltd, publisher: page no 147-152.

5. Adelepilliteri. (2010). Text Book for Child Health Nursing4th Edition: 2002.Wippincon William. New York, 404-410.

6. Alexander, F. B. (2002). "Text Book of clinical obstetrics and gynecology "Black well science Ltd, publisher: page no 147-152.

7. Walker, J.J. (2001). Severe preeclampsia - best practice \& research in clinical. Journal of Obstetrics \& Gynecology, 14(1):57-71.

8. Munirathnamma, M., Lakshmamma, T. (2013). Knowledge of Staff Nurses Regarding Management of Pregnancy Induced Hypertension (PIH). International Journal of Humanities and social Science Intervention, 2(1); 8-12.

9. Kavita, P., Tesfay, A. (2014). To assess the knowledge of staff nurses on emergency obstetric management at Orotta national referral maternity hospital. International Journal of Allied Medical Sciences and Clinical Research (IJAMSCR), 2(4): 287- 93.

10. Teng, S. P., Zuo, T. C., Jummaat, F. B., \& Keng, S. L. (2015). Knowledge of pregnancy danger signs and associated factors among Malaysian mothers. British Journal of Midwifery, 23(11), 800-806.

11. Abareen, S. (2014). A study to assess the effectiveness of structured teaching programme on knowledge \& prevention of Heat Stroke among the adolescent studying in selected high schools at Gulbarga. Int. J. Adv. Nur. Management, 2(1), 2830 . 